"Maryam AlHajri| مريمم الهاجري

\title{
لا مستوطن ولا محلاني: صناعة الأقلّيات الدائمة وتفكيكها
}

Neither Settler nor Native: The Making and Unmaking of Permanent Minorities

$$
\text { عنوان الكتاب: لا مستوطن ولا محلاني: صناعة الأقلّيات الدائمة وتفكيكها. }
$$

عنوان الكتاب في لغته: Neither Settler nor Native: The Making and Unmaking of Permanent Minorities.

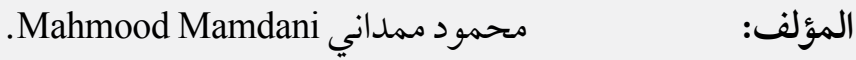

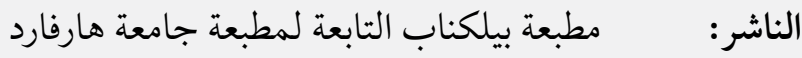

$$
\begin{aligned}
& \text { مكان النشر: } \\
& \text { سنة النشر: }
\end{aligned}
$$

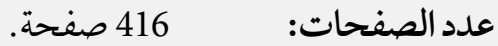


يناقش المؤلف في مقدمة الكتاب "السيرة الذاتية" للدولة الحديثة لحظة ولادتها، ويُقدّم مداخلة

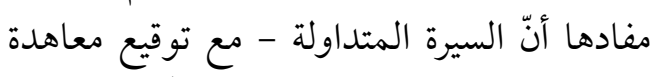

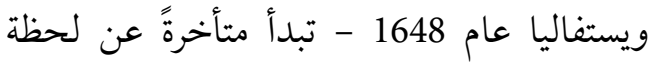
الولادة الفعلية، التي يترتب عليها تقديم دروس

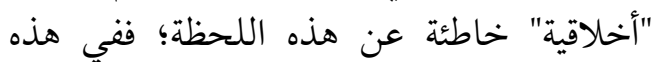

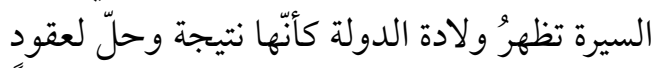

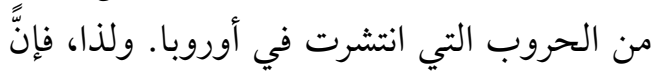

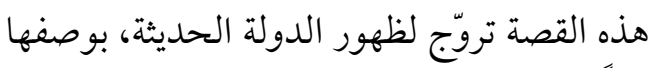

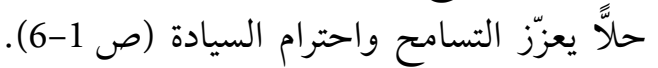

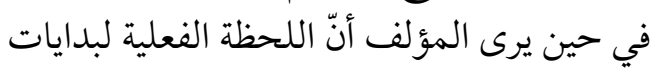

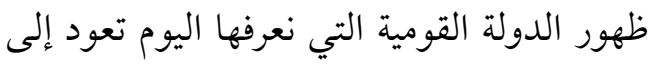
عام 1492 في أيبيريا، وأنهّا أسست لتعرفية التطور ظاهرتين

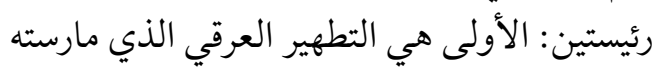

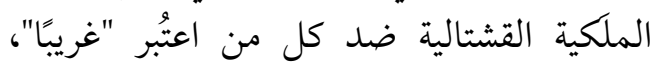

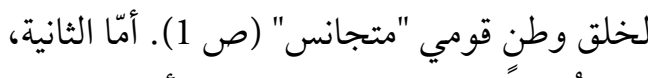

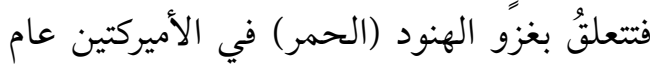
1492، والقيام بعمليات التطهير العرقي ذاتها التي التي التئي

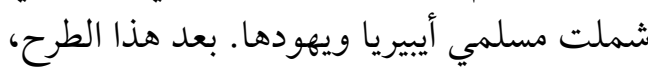

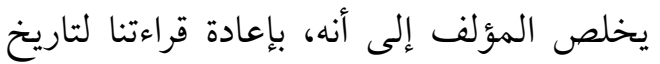

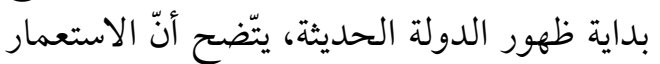

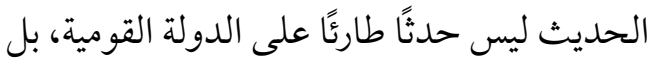

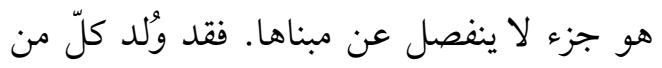

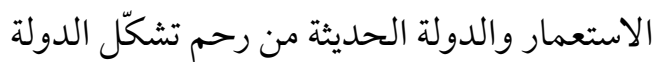

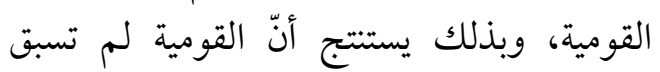

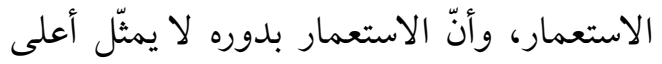

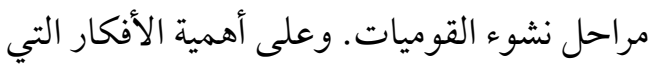

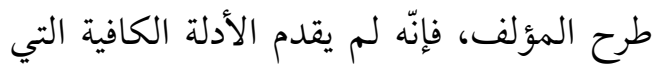

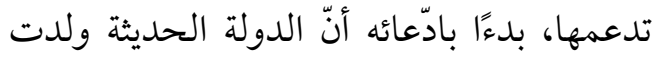

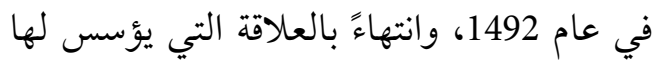
بين القومية والاستعمار، وهو الادّعاء الذي يحتاج

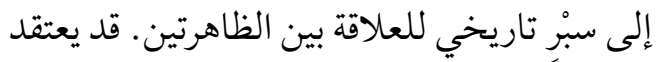
القارئ في هذه المرحلة أنه يقرأ، فيما سيأتي،
مقدمة

يأتي كتاب لامستوطن ولا محلاني: صناعة الأقلّيات الدائمة وتفكيكها"(1)،

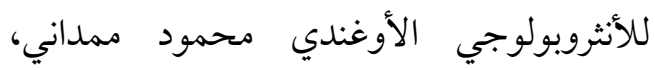

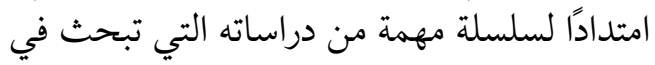

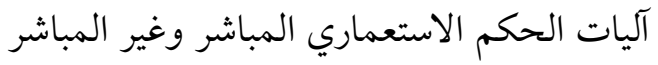

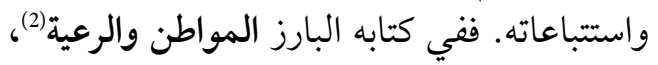

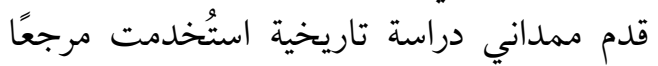

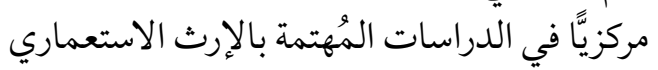

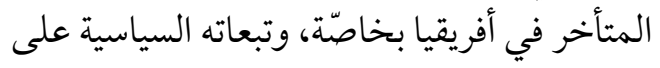
دول ما بعد الاستعمار بعامّة.

في هذا الكتاب، يعود ممداني إلى الاشتغال

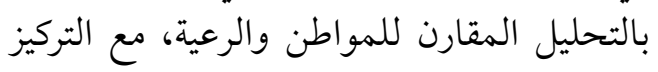

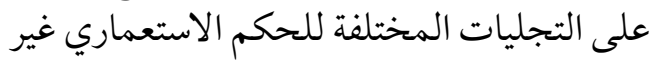

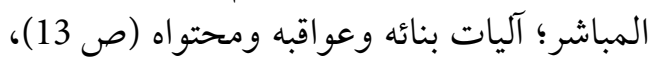

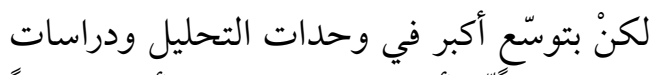

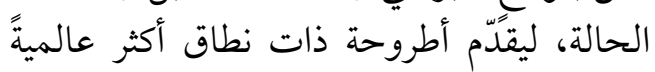

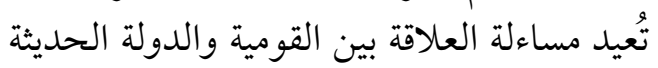

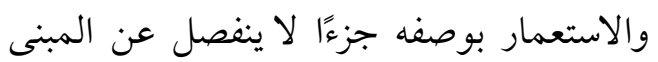

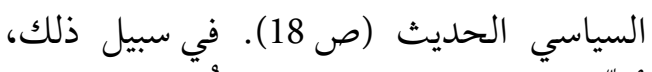

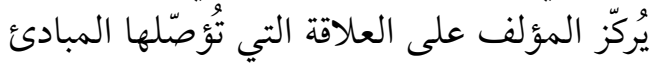

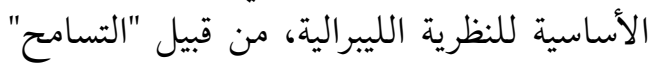

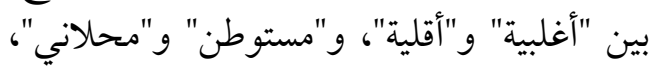

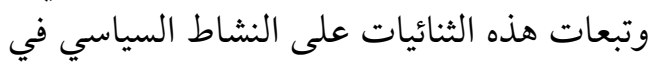

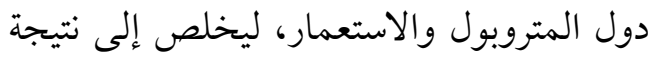

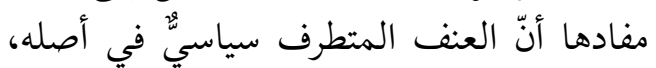

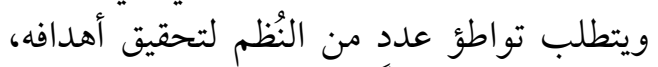
وهو ليس قاصرًا على" عمل إجرامي و / أو فردي. لتحئ أهدافي

(1) Mahmood Mamdani, Neither Settler nor Native: The Making and Unmaking of Permanent Minorities (Massachusetts/ London: Belknap Press of Harvard University Press, 2020).

(2) Mahmood Mamdani, Citizen and Subject: Contemporary Africa and the Legacy of Late Colonialism (Princeton: Princeton University Press, 1996). 
ينتقل بعدها المؤلف إلى مساءلة عنف الدولة

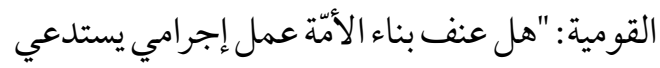

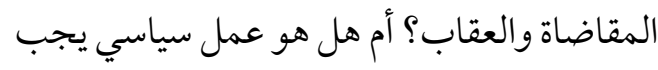

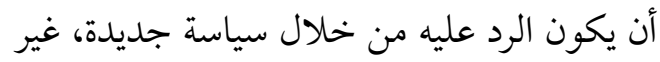

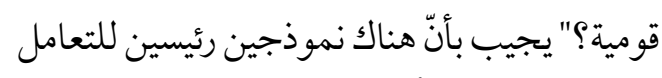

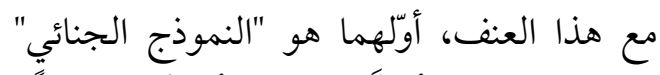

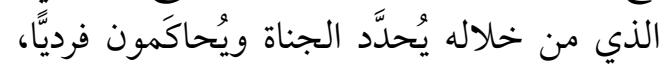

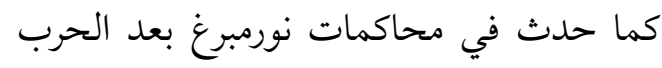

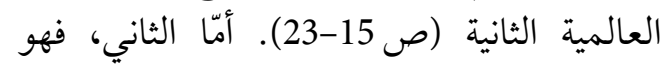

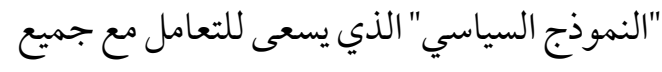

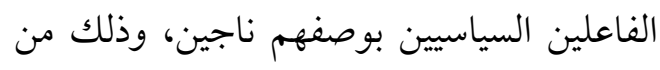

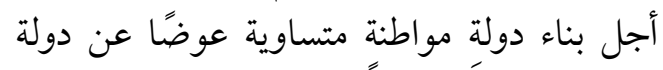

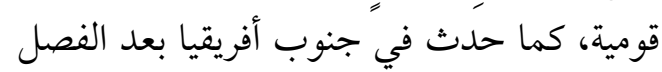
العنصري (ص 15-16). والإنجاز العظيم لحركة آفريفا بعد الفصل

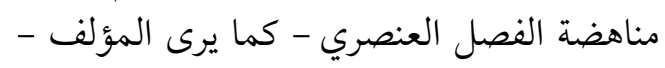

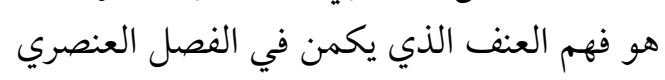

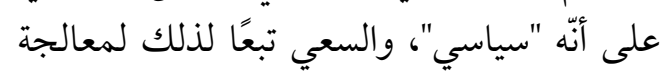

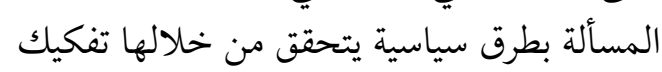
الاستعمار السياسي؛ وهذا المنحى اتِّذ مسارًا

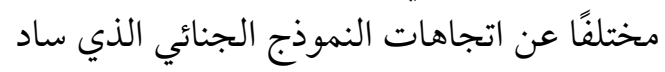

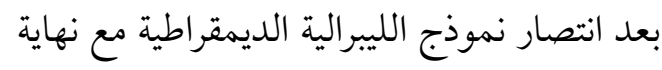

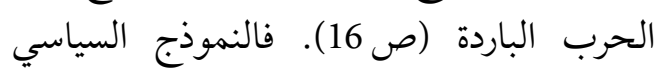

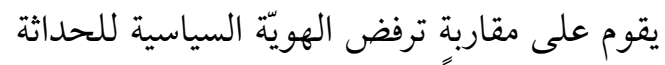

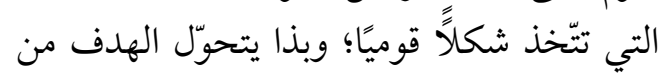
بناء دولة قومية إلى بناء دولة مواطنين متساوين. ويرى المؤلف أنّ هذه اللحظة كانت هي النهاية دولة دواطنين

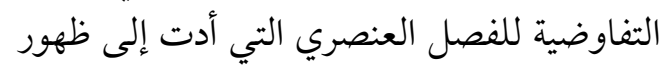

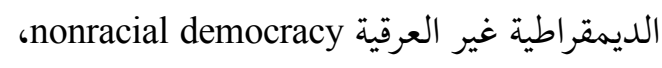
والتي كان من الممكن أن يسعى النهج الجنيائي

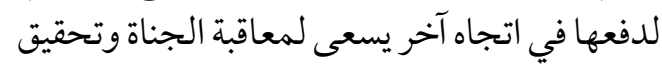

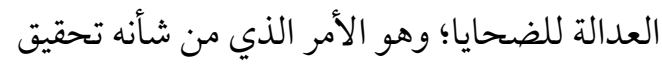
عدالة لحظية لن تُّهم في الدفع نحو إصلاح سياسي مستدام (ص 16-17). وفي هذا السياق،
التاريخَ التفصيلي لهذه العلاقة، ولكنه لا يكاد

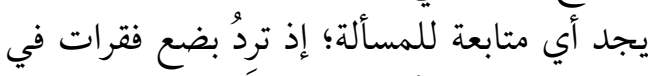
المقدّمة ما تلبث أن تتلاشى في بَاقي الكتاب. يقدّم المؤلف حجة أساسية أخرى، وهي أنّ مفهوم

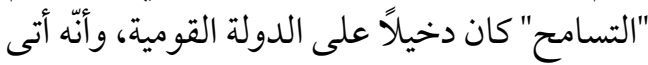

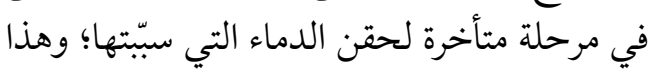

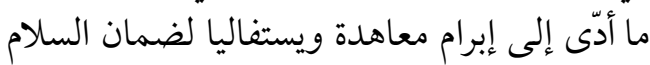

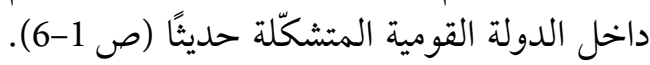

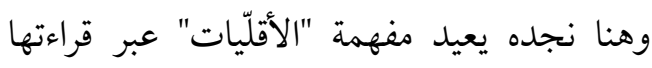
في ضوء "التسامح" الناشئ بدوره مقابل الولاء السياسي، والذي عنى المعادلة الآتية: التسامح

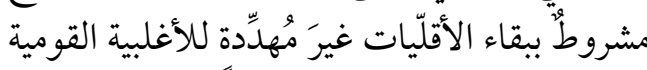

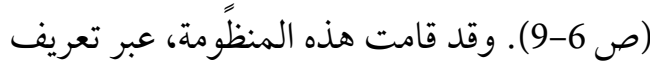

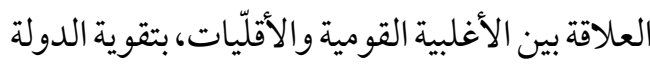

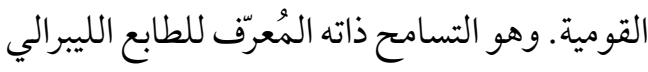

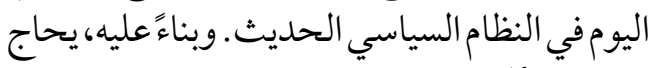

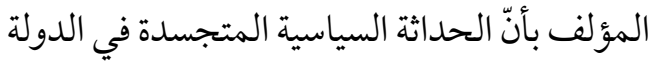

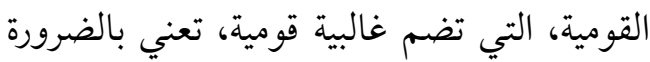

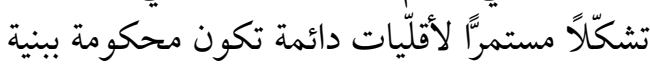

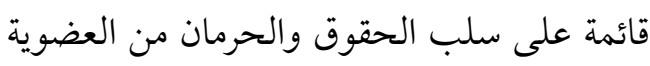
في الدولة القومية. من هنا، يتّلَح أنّ مبنى الدولة

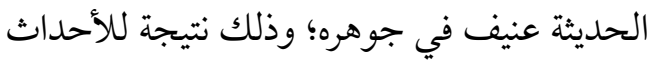
التي أسست لظهورها، من تطهير عرقيّ وإبادات

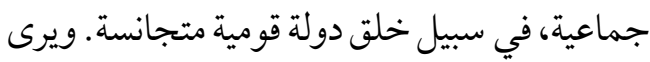

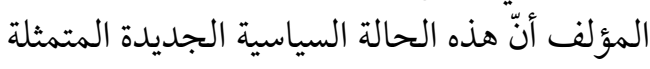
في الحداثة، التّي تتمركز - في أصلها وأيديولوجيّيتها

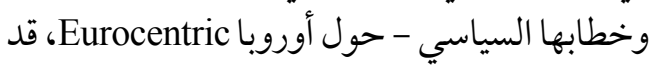
اتِخذت شكلاً مختلفًا في المستعمرات الأوروبية.

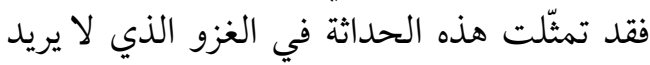

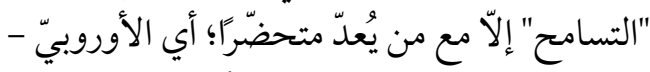

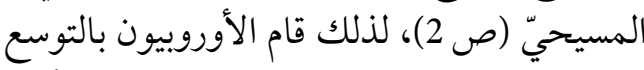

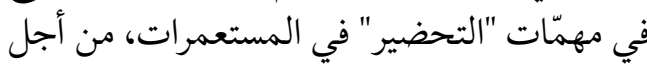

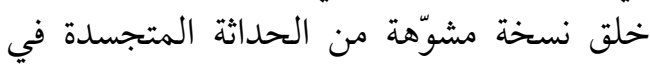

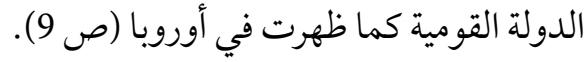


الجماعية، من قبيل تحسين النسل، التي روّجَ

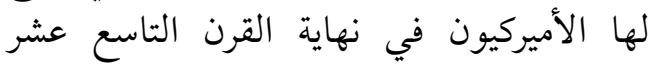

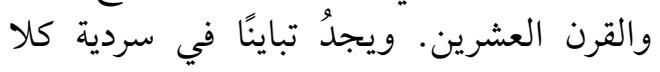

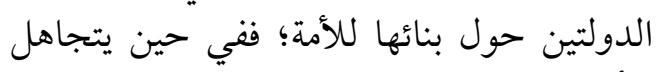

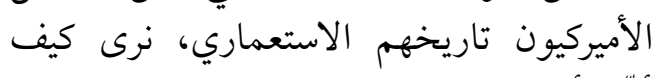

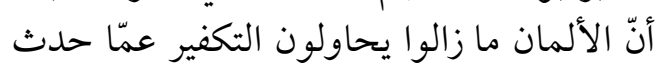

(ص ان الان مان (37-39).

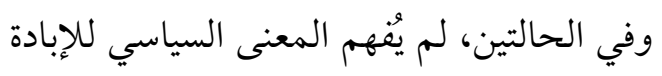

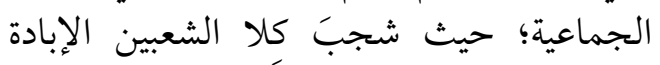

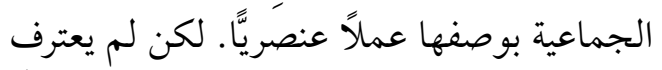

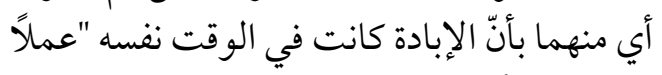

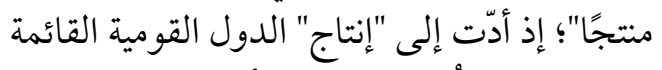

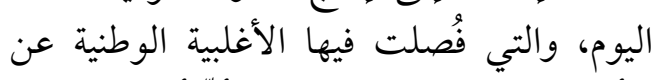

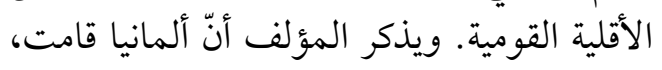

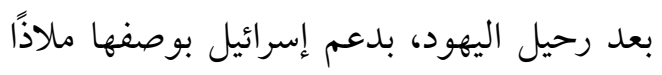

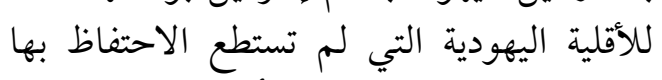

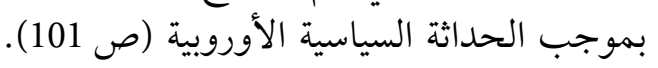

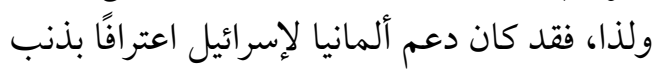

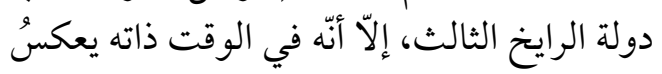

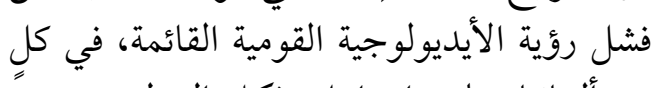

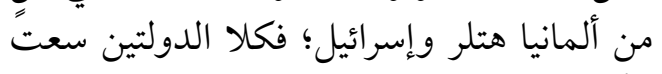
لتأسيس وطن لقومية متجانسة (ص ألمانيان 102-103).

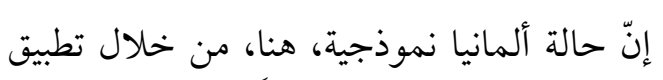

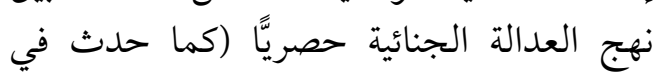

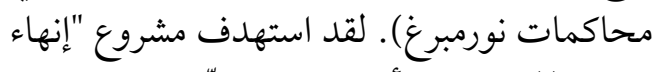

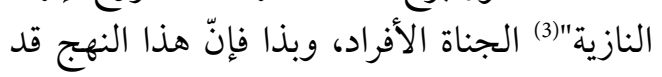
أهمل مساءلة المؤسسات والهياكل الاجتماعية الأنية

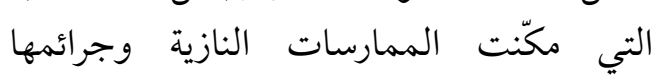

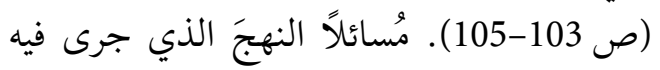

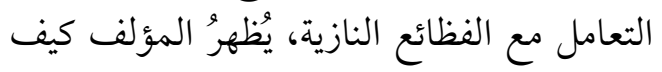

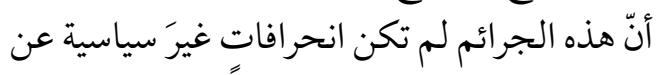

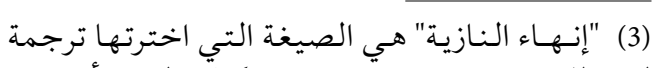

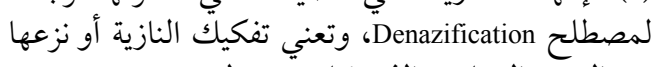
عن المبنى السياسي الذي كانت تنشط فيه.
يُبسّط المؤلف مداخلته، عبر استعراض سلسلة من دراسات الحالة على امتداد ستّة فصول.

\section{أولاً: "سؤال الهـود الحمـر في} الولايات المتحدة" المالوات

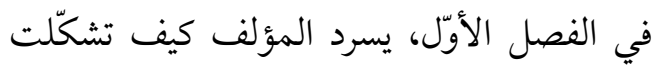

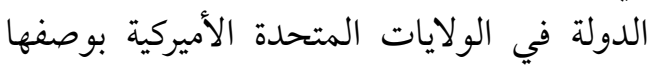

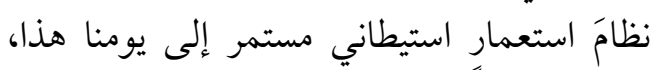

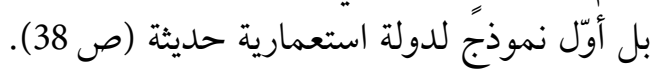

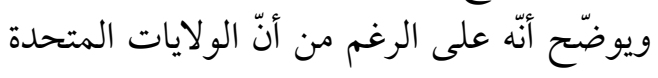

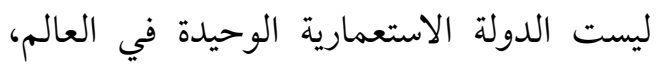

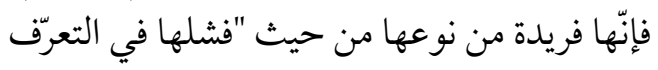

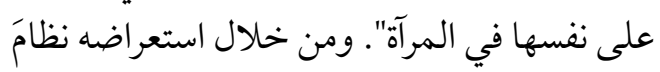
المحميات، الذي يحكم الأمريكيين الأصليين الذئن

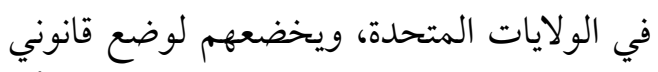
يجعلهم مواطنين من درجة ثانية ومحرومين من أيّ ليّي

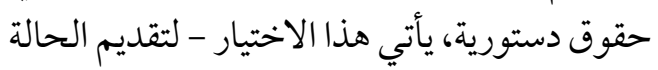
الأميركية على بقية الحالات الأخرى - لتبيان الكيفية

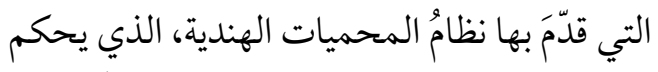

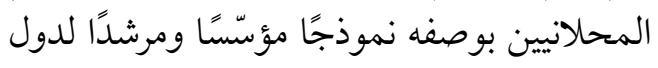

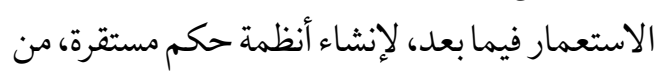

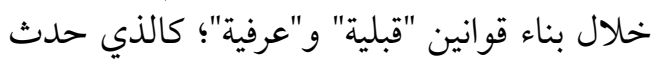

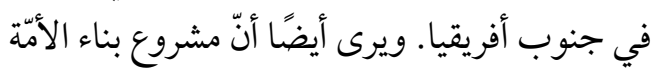

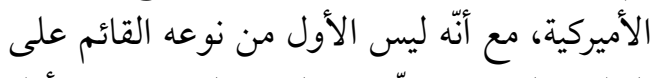

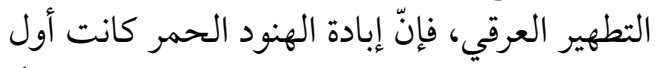

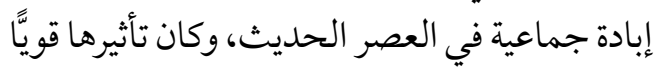
في أماكن أخرى أهمها ألمانيا النازية (ص 32) الثران تأيرها

\section{ثنانيًا: "نورمبرغ: فـلثل إنهاء "النازية}

يستهلّ المؤلف الفصل الثاني بإظهار الكيفية

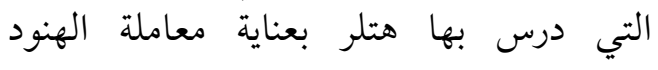
الحمر في الولايات المتحدة، وتبريرات الإبادة 
المحلاني؛ فهو "الآخَرَ" الذي اخترعه المستوطن

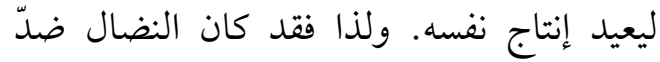

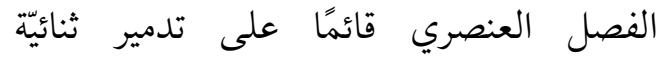
المستوطن والمحلاني من خلال إعادة تشكيلهما

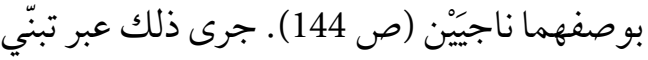

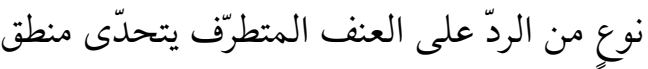

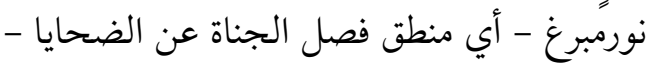

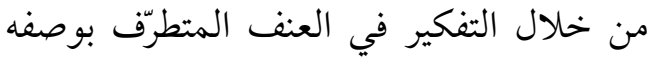

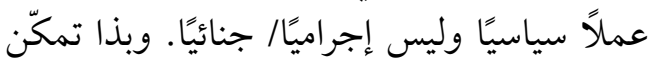

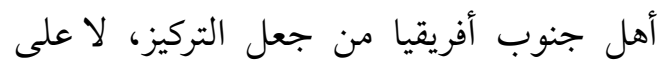
التجاوزات الفردية للقانون بل على التى مساءلة

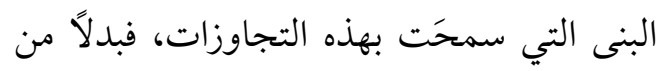

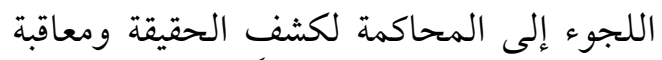

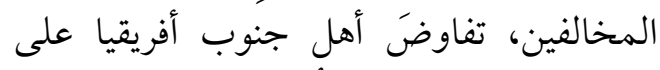

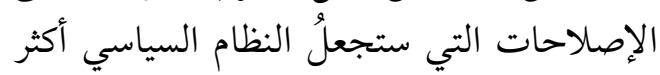

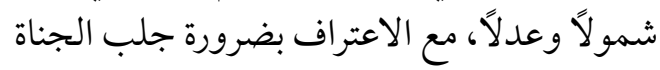

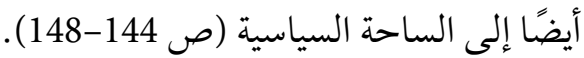

رايعًَا:"السودات: الاستتعمار والاستققلال والانفصال"

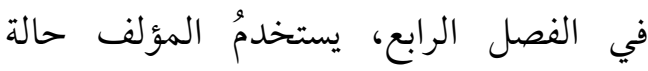

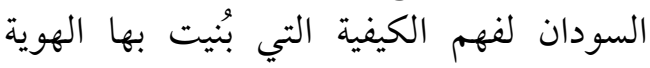

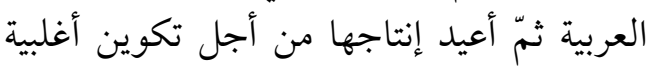

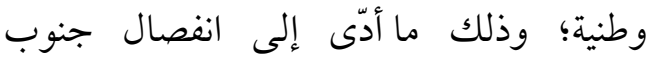
السودان حينما استحال إنشاء "سودان جديد إلفيدان

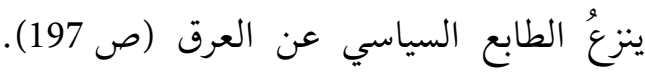

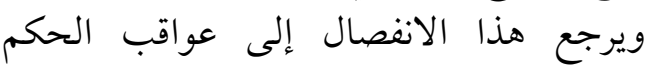

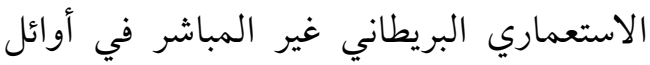

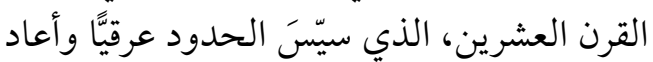
تشكيل الاختلاف الثقافي بوصفه اختلافًا قَبَلَّاًا

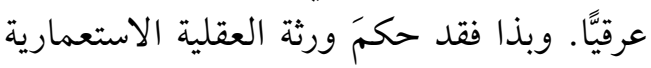

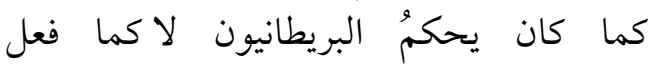

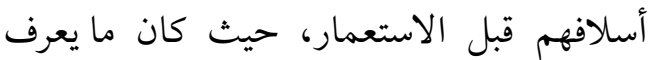

الحداثة، بل كشفت عن جذور الإبادة الجماعية

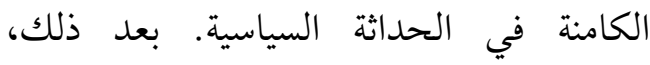

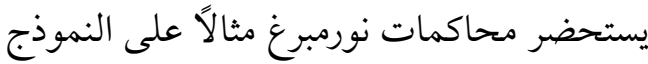

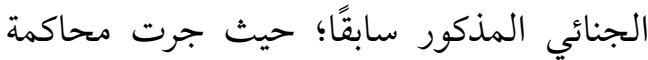

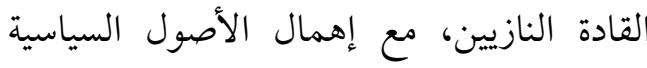
للهولوكوست، أي الدولة القومية التي لم يُشكّ الهيك فيها قط (ص 26-27).

\section{ثالثًا:"المستوطنون}

\section{والمحلانيون في دولة الفصل} العنصـري في جنـوب أفـريقيا" في الفصل الثالث، يُبيّن المؤلف كيف يُمكن نزع

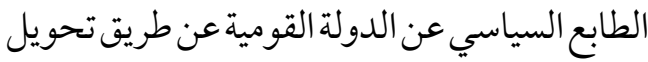

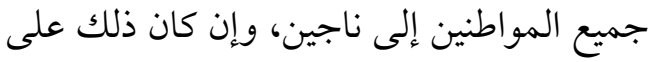
المستوى العرقي فقط، حيث تظلّ الهويات القبَليّة

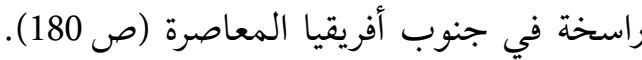
وعلى عكس ألمانيا، فقد تعامل المجتمع المدني المعاصي (اصني

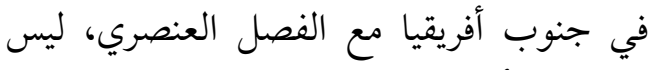

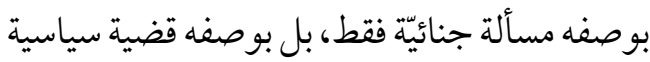

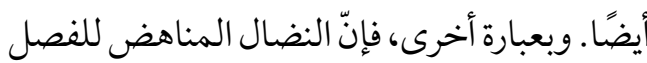
العنصري في جنوب أفريقيا، بدلاً من سعيه للعثور

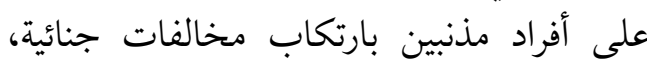
قد سعى لتأسيس نظام سياسي جديد باديد، يُمكن فيه للجميع المشاركة خارج قواعد نظام الفصل العنصري السياسي. وبقدر ما كانت هذه العملية

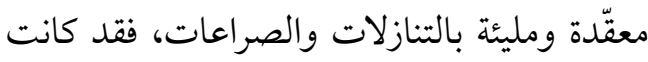
تدلّ على الوعد بإنهاء الاستعمار وتفكيكه.

في هذا السياق، يعود المؤلف إلى محاضرة

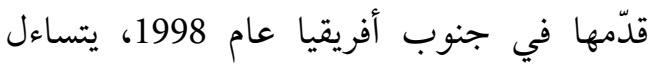

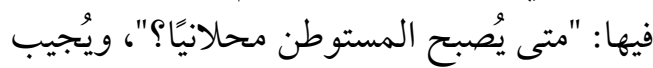

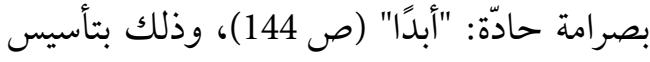

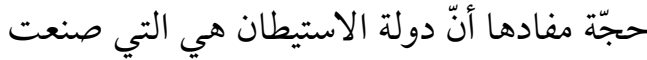




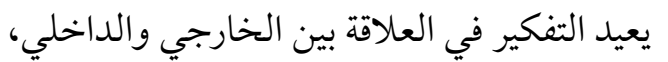

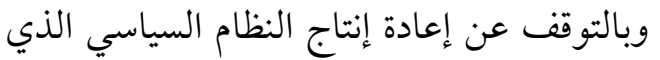
أنشأه الاستعمار البريطاني (ص 248).

\section{خامسسا: "السلؤال الإسـرائيلي/} الفلسطيني"

يُركّز المؤلف في الفصل الخامس على الحالة

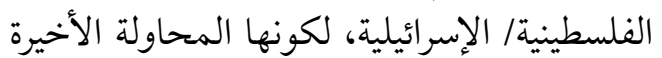

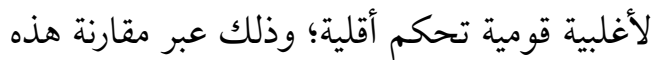
الحالة بحالة جنوب أفريقيا التي تقدم دروسًا مهمّة

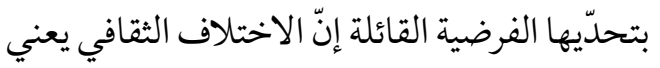

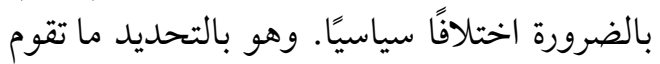

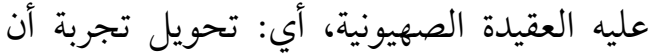

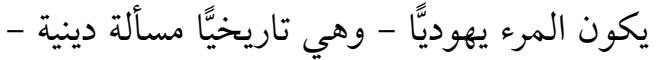

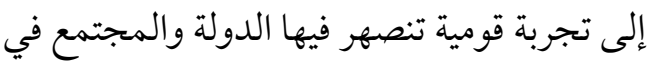

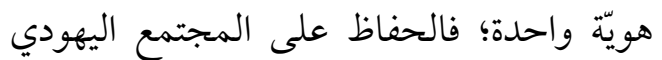

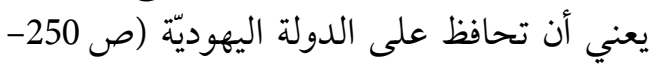

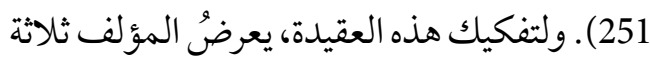

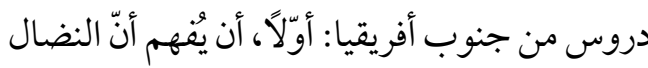

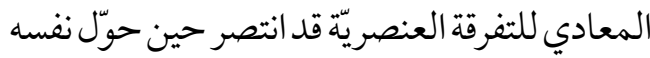

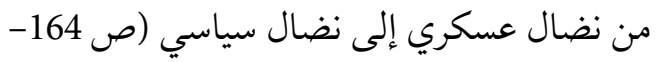

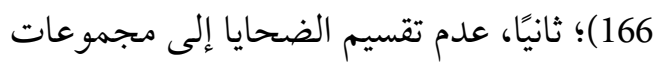
منفصلة، بل توحيدها (ص 148-148-149)؛ ثالثًا،

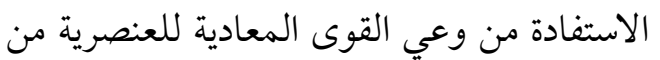

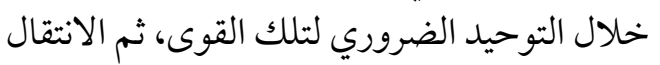
إلى تحالف أوسع يضمّ البيض (ص 169-190).

يُناقش المؤلف الصهيونية بوصفها تطبيقًا متكاملاً

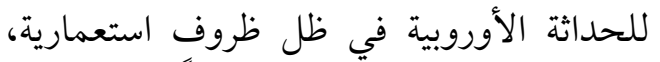

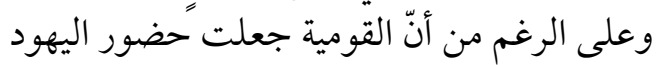

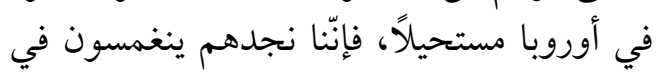

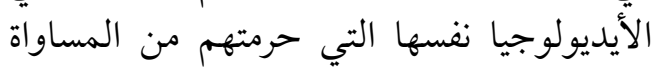

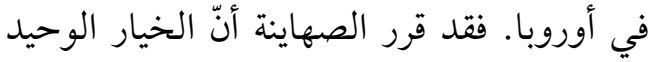

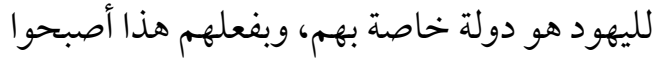

الآن بالسودان وجنوب السودان موطنًا للتنوع

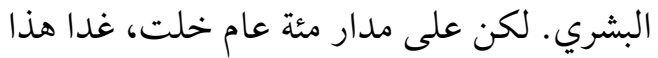

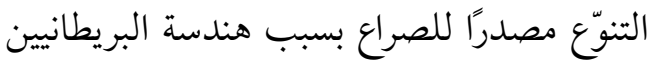

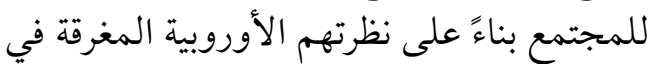

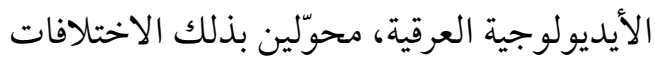

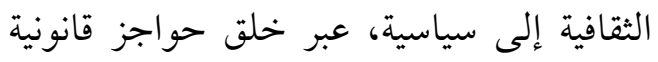
ومادية بين الجماعات - التي كانت مختلطة الترانية

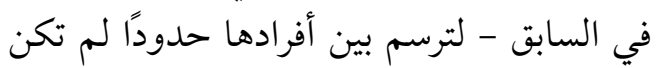
موجودة من قبل، ما منعهم من تطوير تضامنيات خارج القبيلة (ص فو 200-201).

لقد استفاد المشروع الاستعماري في السودان

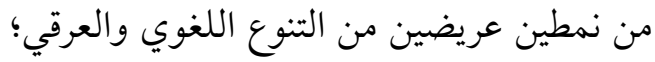

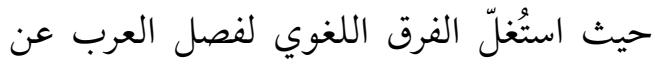

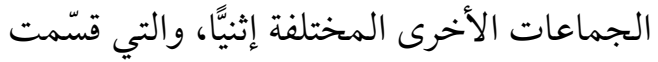

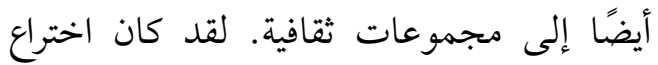
هذا التمييز بين المستوطنين والمحلانيين نتاجئا للأيديولوجية والقانون معًا، إلاّ أنّ التاريخ كانين التين ناجنا

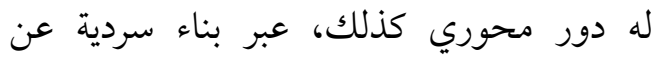
ماضي السودان الثقافي، في خلق هويّات جديدة عيدة

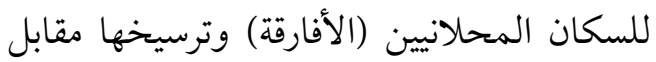

$$
\text { المستوطنين (العرب) (ص لانين (لأفارة وترسيخان }
$$

وبناءً عليه، يرى المؤلف أنّ الاستعمار لن ينتهي

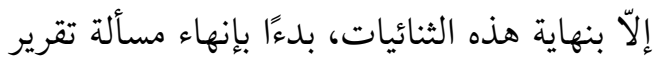

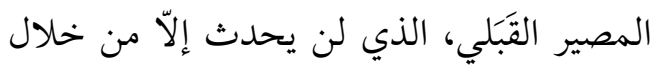

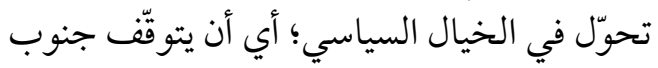

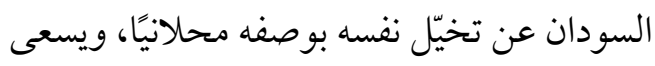

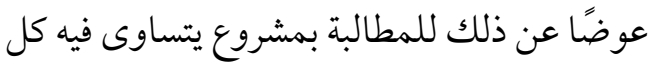

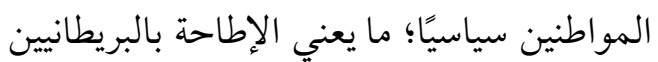

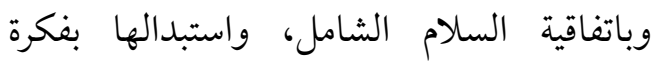
الدولة دون الأمّة (ص 246-249). من هنا يبدأ إنهاء الاستعمار السياسي في السودان وجنوب السون السودان؛ وذلك بخلق تاريخ جديد من الداخل السئل 
العنف، الذي يرى أنّه سياسي بامتياز وأنّه ينطلق من

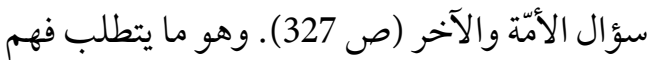

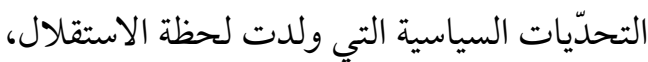
والاعتراف بالتبعات والآثار السياسية للاستعمار الذي لم يقتصر دوره على رسم الحدود الخارجية

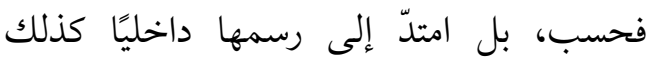

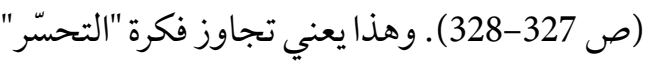
على الحدود التي قسّمت المجتمعات المدات المتشابهة

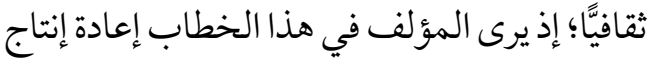

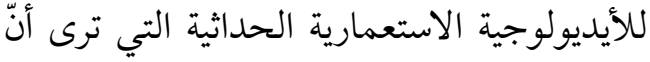
الحدود يُقترض أن تبنى على أساس إثني - عرقي.

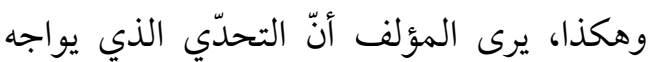

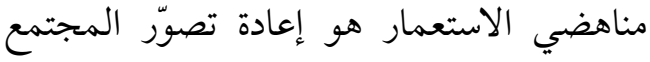

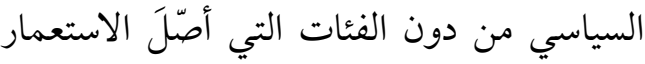

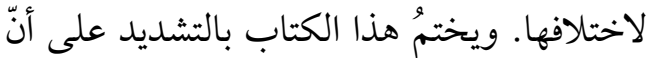

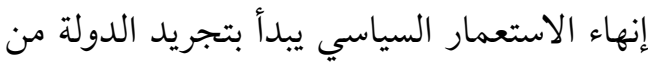

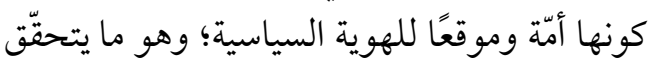

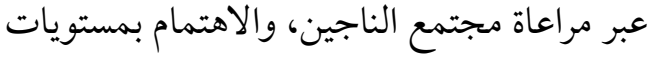
الإقصاء التي هي نتيجة ضرورية لتشكّل الدولة القومية (ص 330).

\section{ملاحظّات نقدية}

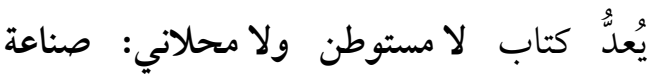

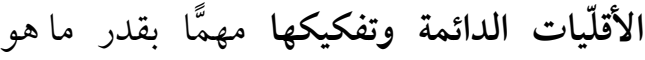
إشكالي، للاعتبارات التالية:

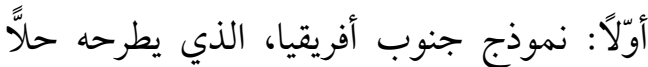

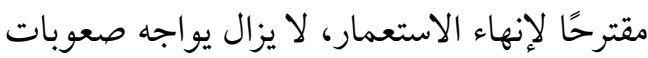

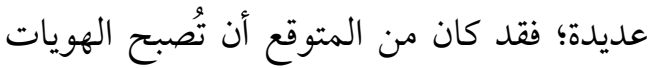

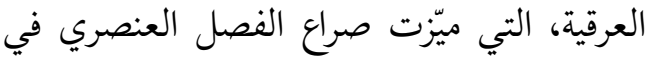

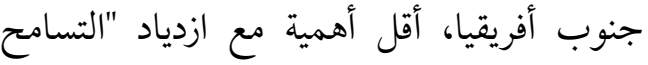

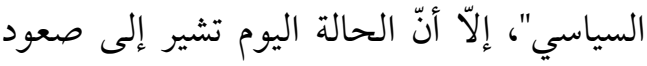

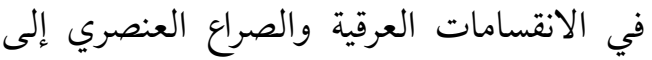

"هم الظالمين، لأنّ المرء في الدولة القومية يُمكنه

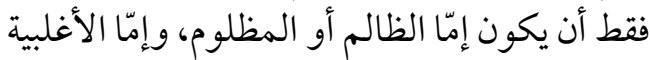
أو الأقليّة، وإمّا الأمة أو الآخر " (ص 251).

ويوضّح المؤلف أنّ اليهود العرب بالتحديد يمثّلون تحديًّا خاصَّا للصهيونيّة؛ لأنّها تفترض أنس أنّ الهويّيّين

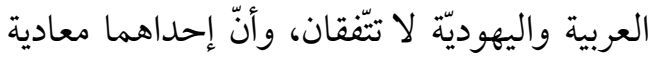
للأخرى حتمًا، وإلا لما كانت هناك الكان حاجة إلى إلى دولة يهودية في فلسطين التاريخية (ص 253).

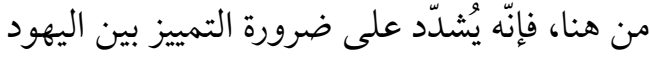

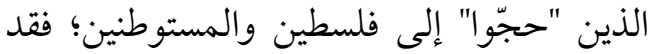

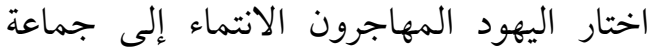

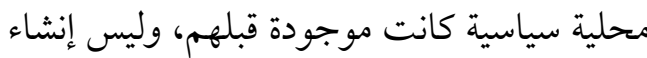
جماعتهم الخاصة (ص 253). لقد أدّت الجهود

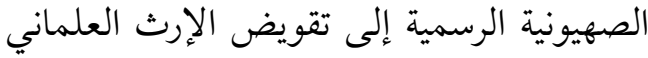

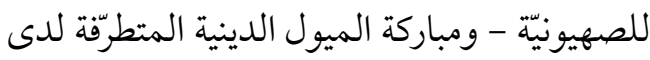
كل من المزراحيم وجاليات أخرى - ما أدّى إلى الى الى الدئي

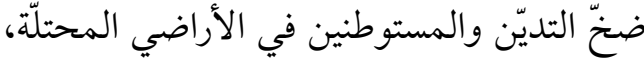
وهو الأمر الذي يرى المؤلف أنه "أجّجَج الإحساس الدئ بوعي وطني فلسطيني" (ص 245-255). يختمُ المؤلف هذا الفصل بنقاش حول حل الدولتين - الذي انتهى - مع اتفاق أوسلو، داعيّ الفيًا فيه

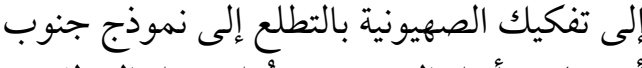

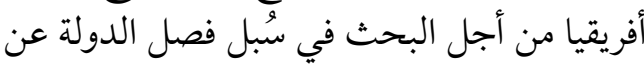

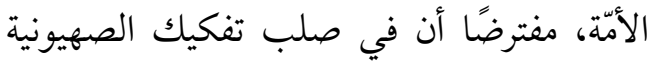

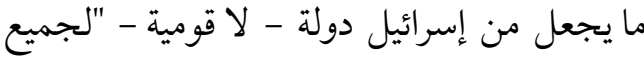
مو اطنيها" (ص من 255).

\section{سادسًا: "تفكيك استعمار} المجتمع السياسي" يعيد المؤلف، في الفصل الأخير، قراءة العنف

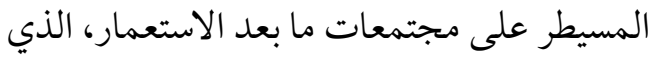

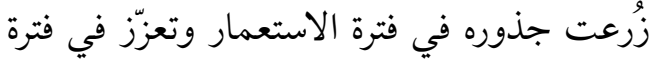
ما بعد الاستقلال، من خلال أشكلة نوع هذار فئرة فئرة 
والسيادة في عالم ينتظم على نحوِ متزايد حول الدولة القومية (6).

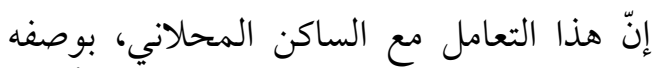

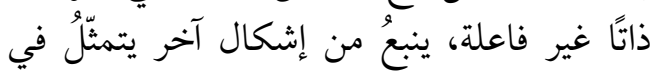

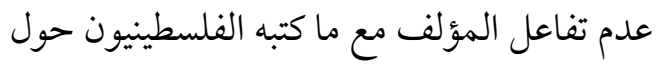

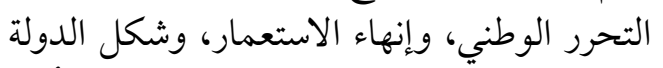

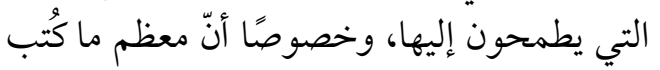
يخلص إلى استنتاجات مختلفة، بل معاكسة لما لماك

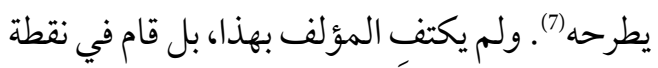

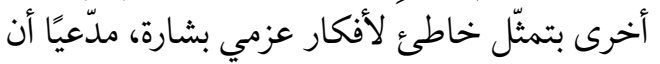
بشارة كان يدفع نحو مشروع دولة دون أمّلة، مستشهيدًا

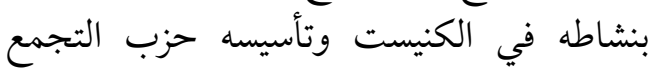

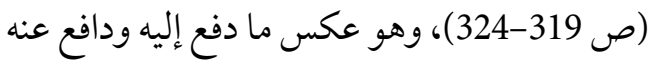
بشارة، الذي كانت مساهمته في النضال الفلسطيني

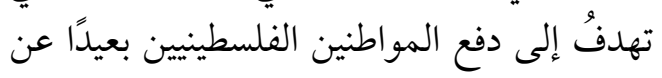

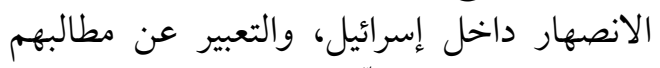

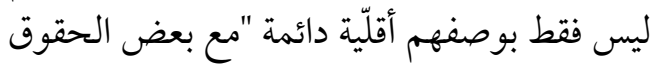

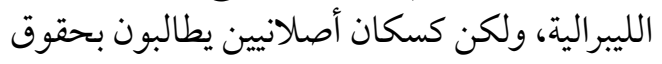

جماعية ويؤكدون هويّتهم الوطنية الفلسطينية" (8).

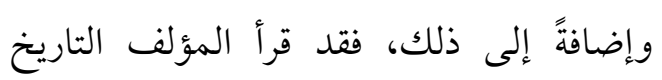

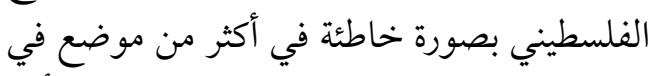

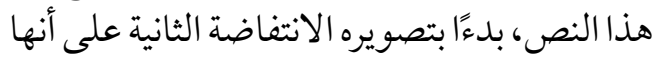

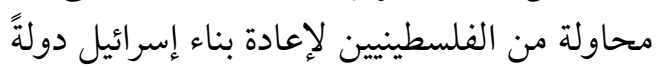

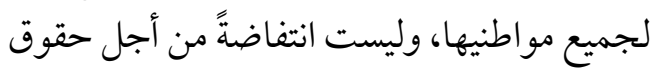

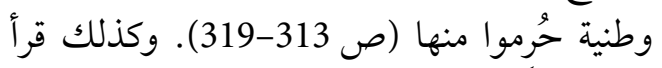
الانتفاضتينَ الأولى والثانية، بوصفهما كفاحًا من

(6) أستعين في هذه النقطة بمراجعة دانا الكرد، التي بالرغم

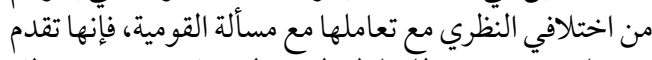

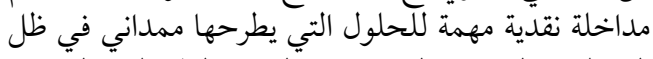

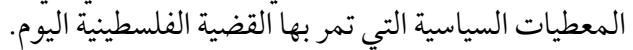

Dana El Kurd, "Do Palestinians Really Want a South African Solution?" +972 Magazine, 14/7/2021, accessed on 13/9/2021, at: https://bit.ly/31fD4MI

(7) Ibid.

(8) Ibid.
القدر ذاته من الخطورة - إن لم يكن أكثر ممّا كان

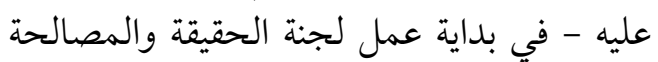
TRC

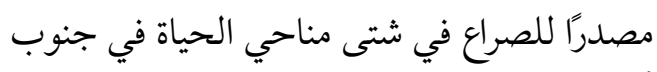

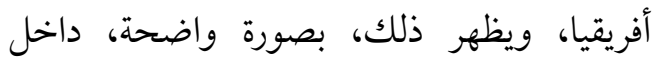

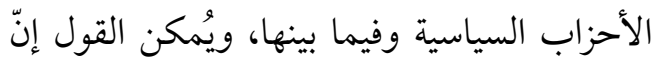

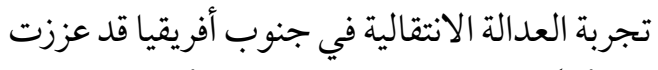

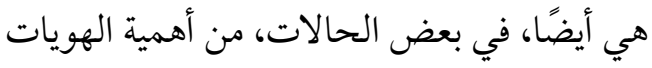
العرقية والإثنية (5). ثانيًا: تأسيسًا على ما سبق، هناك إشكال صريح

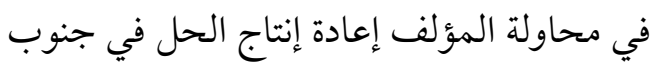

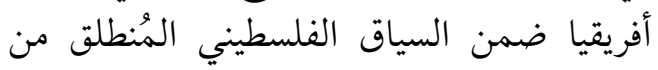

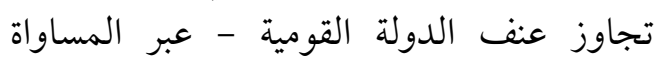

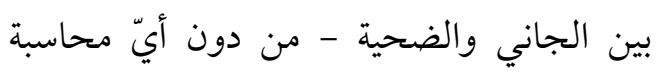
أو معاقبة، وبلا توضيح لكيفية القيام بذلك من الضحن دون إعادة أنظمة عدم المساواة وتكريسها.

ثالثًا: رغم فكرة أنّ القومية التي ولدت، ظاهرةً

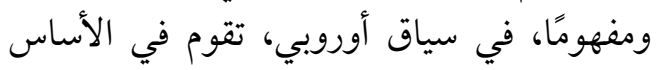

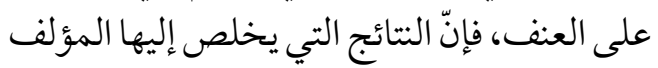
انطلاقًا من هذه الحجة إشكالية، وخصوصًا لأنّنّا نستعملها في سياق دولة استيطانية استعمارية -

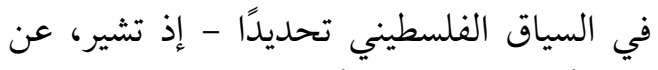

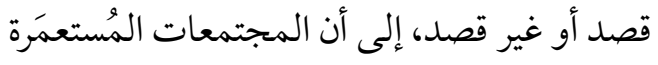
لم تكن لديها سلطة أو رأي في تطوير هويّاتها.

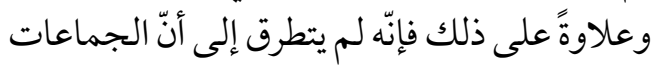

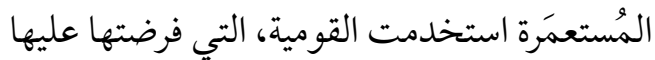
الحداثة، وسيلةً للتحرر والمطالبة بتقرير المصية، فرضير

(4) Deborah Posel, "Race as Common Sense: Racial Classification in Twentieth-Century South Africa," African Studies Review, vol. 44, no. 2 (2001), pp. 87-114.

(5) Karen E. Ferree, Framing the Race in South Africa: The Political Origins of Racial Census Elections (Cambridge: Cambridge University Press, 2010), pp. 92103. 


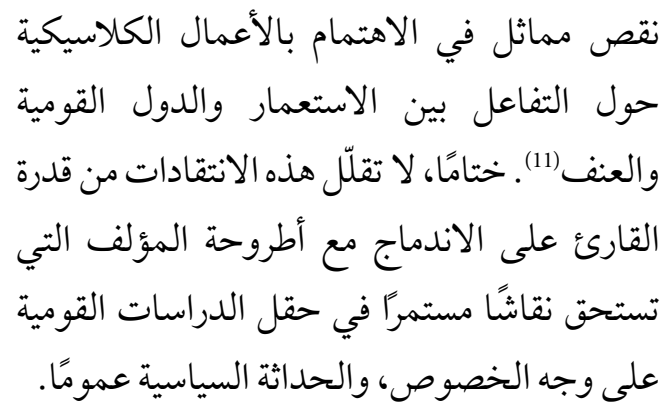

(11) Étienne Balibar \& Immanuel Maurice Wallerstein, Race, Nation, Class: Ambiguous Identities (London: Verso, 1991); Homi K. Bhabha, The Location of Culture (London: Routledge, 1994), ch. 8 "DissemiNation: Time, Narrative and the Margins of the Modern Nation"; Partha Chatterjee, "Whose Imagined Community?," Millennium, vol. 20, no. 3 (March 1991), pp. 521-525; Partha Chatterjee, The Nation and Its Fragments: Colonial and Postcolonial Histories (Princeton: Princeton University Press, 1993).

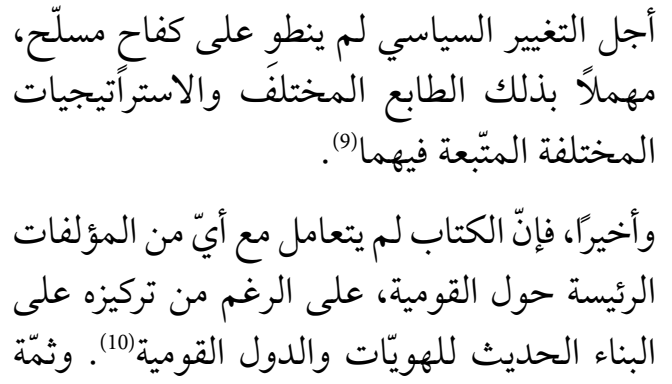

(9) Ibid.

$$
\text { يُنظر على سبيل المثال: }
$$

Benedict Anderson, Imagined Communities: Reflections on the Origin and Spread of Nationalism (London: Verso, 2006); Ernest Gellner, Nations and Nationalism (Oxford: Blackwell, 2006); Michael Mann, The Sources of Social Power (Cambridge: Cambridge University Press, 1986); Anthony D. Smith, The Ethnic Origins of Nations (Oxford: Basil Blackwell, 1986).

\section{المـراجع}

Anderson, Benedict. Imagined Communities: Reflections on the Origin and Spread of Nationalism. London: Verso, 2006.

Balibar, Étienne \& Immanuel Maurice Wallerstein. Race, Nation, Class: Ambiguous Identities. London: Verso, 1991.

Bhabha, Homi K. The Location of Culture. London: Routledge, 1994.

Chatterjee, Partha "Whose Imagined Community?." Millennium. vol. 20. no. 3 (March 1991). The Nation and Its Fragments: Colonial and Postcolonial Histories. Princeton: Princeton University Press, 1993.

El Kurd, Dana. "Do Palestinians Really Want a South African Solution?" +972 Magazine. 14/7/2021. at: https://bit.ly/31fD4MI

Ferree, Karen E. Framing the Race in South Africa: The Political Origins of Racial Census Elections. Cambridge: Cambridge University Press, 2010.

Gellner, Ernest. Nations and Nationalism. Oxford: Blackwell, 2006.

Mamdani, Mahmood. Citizen and Subject: Contemporary Africa and the Legacy of Late Colonialism. Princeton: Princeton University Press, 1996.

. Neither Settler nor Native: The Making and Unmaking of Permanent Minorities. Massachusetts/ London: Belknap Press of Harvard University Press, 2020.

Mann, Michael. The Sources of Social Power. Cambridge: Cambridge University Press, 1986.

Posel, Deborah. "Race as Common Sense: Racial Classification in Twentieth-Century South Africa." African Studies Review. vol. 44, no. 2 (September 2001).

Smith, Anthony D. The Ethnic Origins of Nations. Oxford: Basil Blackwell, 1986. 